\title{
Pelatihan Pembuatan dan Pendampingan Penerapan Multimedia Genggam Si Dio (Camtasia Studio) Berbasis Android bagi Tutor PKBM di Kabupaten Kuningan
}

\author{
Dyah Puteria Wati' ${ }^{1}$ Dede Cahyati Sahrir ${ }^{2}$, Ahmad Fajri Lutfi ${ }^{3}$ \\ ${ }_{1,3}$ STKIP Muhammadiyah Kuningan, ${ }^{2}$ IAIN Syekh Nurjati Cirebon
}

\begin{tabular}{|c|c|}
\hline ARTICLE INFO & ABSTRACT \\
\hline $\begin{array}{l}\text { Article History: } \\
\text { Received 10.06.2018 } \\
\text { Received in revised } \\
\text { form } 12.09 .2018 \\
\text { Accepted 30.11.2018 } \\
\text { Available online } \\
\text { 21.12.2018 }\end{array}$ & $\begin{array}{l}\text { Equality education of study group Package } C \text { is one of the non-formal } \\
\text { education programs for people's equivalent to high school level. One of the } \\
\text { problems faced in the learning process of Package } C \text { program held by PKBM } \\
\text { Kuningan city is not maximize the use of learning media, especially in the } \\
\text { field of technology. This community service activity will be held in PKBM } \\
\text { Kuningan city which already has NPSN. The purpose of this training is to } \\
\text { improve tutor skills in making and implementing learning by utilizing } \\
\text { android-based smartphone as a medium of learning. The method of training } \\
\text { implementation consists of several stages: training licensing, training } \\
\text { preparation, preparation of training module book, Si Dio handheld } \\
\text { multimedia training, mentoring of media usage already made by tutor. Based } \\
\text { on the results of training and mentoring the application of handheld } \\
\text { multimedia Si Dio based on android this can help improve and improve the } \\
\text { quality of the process of Package } C \text { equivalence program and facilitate } \\
\text { understanding even though learners learn independently. }\end{array}$ \\
\hline
\end{tabular}

Keywords: Android, Camtasia Studio, Mentoring, Training, Tutor. Commons Attribution 4.0 International License, which permits unrestricted use distribution, and reproduction in any medium, provided the original work is properly cited. @ 2018 Dyah Puteria Wati, Dede Cahyati Sahrir, Ahmad Fajri Lutfi.

\section{PENDAHULUAN}

Pendidikan kesetaraan merupakan salah satu program pendidikan nonformal untuk masyarakat yang meliputi program kelompok belajar paket A setara SD, kelompok belajar paket B setara SMP dan kelompok belajar paket C setara SMA (Disdik, 2008). Pendidikan kesetaraan dimulai pada tahun 1980-an ketika pemerintah mencanangkan wajib belajar sembilan tahun, yaitu enam tahun di SD dan tiga tahun di SLTP atau yang sederajat. Dalam perkembangan selanjutnya program Paket $C$ juga diperuntukkan bagi siswa sekolah formal yang tidak lulus SMA dan lulusan SMP yang ingin melanjutkan ke SMA. Sebagai bentuk pengakuan terhadap program Paket C, pada tahun 2001 untuk pertama kali pemerintah menyelenggarakan ujian nasional Paket $C$ yang kemudian pengakuan 
pengesahannya dilakukan pada tahun 2004 (Depdiknas, 2006). Adapun pelaksana kegiatan pembelajaran pada program Paket adalah Pusat Kegiatan Belajar Masyarakat (PKBM). PKBM di Kabupaten Kuningan tersebar hampir di seluruh kecamatan.

Kedua mitra (PKBM Miftahul Janah dan PKBM Assyifa) mengadakan program Paket $\mathrm{C}$ dengan jumlah rombel yang sama, yaitu sebanyak 6 rombel, dimana masing-masing mata pelajaran diampu oleh tutor yang berbeda. Meskipun belum semua tutor merupakan lulusan yang sesuai dengan mata pelajaran yang diampu, namun sebagian besar tutor memiliki bidang keilmuan yang sesuai.

Mutu layanan dari PKBM Miftahul Janah maupun PKBM Assyifa sudah cukup baik, karena proses pembelajaran berjalan setiap minggu dan selalu ada kegiatan evaluasi berupa ulangan pada setiap akhir Bab maupun Ujian Tengah Semester (UTS) dan Ujian Akhir Semester (UAS). Perbedaannya PKBM Miftahul Janah memadatkan jawal pertemuan hanya 2 hari setiap minggunya, sedangkan PKBM Assyifa menjadwalkan pertemuan 3 hari setiap minggunya. Namun salah satu penyebab tutor tidak memberikan pelayanan dan kinerja yang maksimal sebagai tenaga pengajar adalah belum pernah diadakannya pelatihan dan pendampingan tutor dalam hal peningkatan kualitas proses pembelajaran program kegiatan belajar paket $C$, terutama pelatihan mengenai pembuatan dan pendampingan penerapan multimedia berbasis IT.

Persoalan pembelajaran pada kedua mitra (PKBM Miftahul Janah dan PKBM Assyifa) salah satunya pada tutor yang jarang menggunakan media pembelajaran saat pembelajaran di kelas. Hal tersebut membuat motivasi peserta didik cenderung rendah. Padahal sebagaimana dijelaskan pada uraian analisis situasi pada kedua mitra bahwa pertemuan pada program paket $C$ hanya 2-3 hari dalam satu minggu dan tidak jarang peserta didik berhalangan hadir karena berbenturan dengan jadwal bekerja. Hal tersebut menuntut adanya alternatif atau tambahan materi pembelajaran yang memungkinkan untuk mereka akses secara mandiri, tidak terbatas waktu, dan tentunya menarik, sehingga mereka termotivasi untuk belajar. Dengan demikian perlu kiranya dibuat dan diterapkannya multimedia pembelajaran yang berbasis android, sehingga mudah untuk diakses melalui smartphone. Namun, akar dari persoalan diatas adalah rendahnya keterampilan tutor dalam pembuatan media yang menarik dan dapat digunakan secara fleksibel, terutama multimedia pembelajaran yang berbasis IT. Untuk dapat menyusun multimedia berbasis IT yang menarik, efektif dan fleksibel perlu adanya pelatihan khusus disertai dengan pendampingan penerapannya sehingga perbaikan kualitas proses pembelajaran dapat dimaksimalkan.

Dengan demikian maka persoalan prioritas sesungguhnya yang dihadapi oleh kedua mitra (PKBM Miftahul Janah dan PKBM Assyifa) pada proses pembelajaran program Paket $C$ adalah rendahmya keterampilan tutor dalam pembuatan media yang menarik dan dapat digunakan secara fleksibel, terutama multimedia pembelajaran yang berbasis IT. Hal ini berdampak pada sebagian besar tutor belum menerapkan media pembelajaran sebagai alat bantu transfer pehamanan kepada peserta didik. Tanpa adanya perantara yang baik dalam penyampaian materi pada saat pembelajaran akan menjadikan ketidakbermaknaan dalam sebuah proses belajar (Surjono, 2010). Media yang tersedia hanya berupa modul setiap mata pelajaran. Modul yang digunakan berupa modul cetak full teks yang cenderung monoton dan kurang menarik minat belajar peserta didik. Hadirnya media pembelajaran berbasis IT diharapkan menjadi salah satu terobosan inovatif untuk meningkatkan kualitas proses dan hasil pembelajaran. Perkembangan teknologi informasi dalam era global yang semakin pesat memberikan tantangan tersendiri bagi semua bidang kehidupan. Hampir keseluruhaan aktifitas senantiasa 
bersentuhan secara langsung dengan perangkat teknologi informasi dan komunikasi. Saat ini teknologi sudah semakin maju, oleh karena itu dunia pendidikan non formal juga harus mengikuti perkembangan teknologi terkini. Namun sayangnya bidang pendidikan nonformal belum mampu memanfaatkan kemajuan teknologi tersebut secara maksimal. Salah satu perkembangan teknologi saat ini yaitu smartphone berbasis android yang menurut hasil observasi kepada peserta didik program Paket $C$ dengan rentang umur 1750 tahun sebagian besar mempunyai smartphone berbasis android meskipun tergolong masyarakat dengan kemampuan menengah ke bawah. Smartphone yang saat ini digemari oleh semua umur dapat diupayakan sebagai salah satu media dalam pembelajaran yang menarik dan fleksibel karena dapat diakses kapanpun dan dimanapun. Hal tersebut dapat menjadi inovasi cara belajar peserta didik secara mandiri diluar pertemuan dengan tutor karena pertemuan dalam kegiatan pembelajaran program Paket $C$ di PKBM yang hanya 2-3 hari dalam 1 minggu. Adanya display penjelasan tutor yang dapat direkam dan ditampilkan bersamaan dengan materi akan memudahkan pemahaman meskipun peserta didik belajar secara mandiri.

Identifikasi permasalahan yang dihadapi kedua mitra secara mum adalah sebagai berikut.

1) Tutor sangat jarang menggunakan media pembelajaran, terutama multimedia berbasis IT dalam pembelajaran.

2) Kemampuan dan keterampilan tutor dalam membuat dan menggunakan media berbasis IT masih rendah.

3) Pembelajaran di PKBM membutuhkan media pembelajaran yang efektif dan dapat diakses kapanpun karena pertemuan tidak sebanyak sekolah formal pada umumnya.

4) Belum tersedia dan belum pernah digunakannya multimedia pembelajaran genggam berbasis android yang digunakan dalam pembelajaran di PKBM mitra.

5) Motivasi belajar peserta didik program Paket $C$ masih rendah karena pembelajaran yang mereka rasakan monoton dan kurang menarik.

Penggunaan multimedia tidak hanya untuk pembelajaran mandiri saja, tetapi juga dapat untuk menyelesaikan masalah secara berkelompok. Multimedia pembelajaran dapat membuat peserta didik melatih kemampuan berpikir kritis dan kreatif dalam memecahkan suatu permasalahan secara pribadi maupun kelompok (Winarno, 2009). Kata "multimedia" dapat diartikan sebagai perpaduan harmonis antara berbagai media baik teks (regular maupun hypertext), gambar, grafik, audio, video/film, dan animasi, yang dikemas secara sinergis untuk mencapai tujuan (pembelajaran) tertentu (Kustiono, 2006). Sedangkan menurut Sukamto (Sukamto, 2004) multimedia pembelajaran sebagai suatu gabungan antara teks, gambar, grafis, animasi, audio dan video, serta cara penyampaian interaktif yang dapat membuat suatu pengalaman belajar bagi siswa seperti dalam kehidupan nyata di sekitarnya, Multimedia pembelajaran dapat diartikan sebagai aplikasi multimedia yang digunakan dalam proses pembelajaran. Multimedia pembelajaran berguna untuk menyalurkan pesan (pengetahuan, keterampilan, dan sikap) serta dapat merangsang pilihan, perasaan, perhatian, dan kemauan siswa sehingga secara sengaja proses belajar, bertujuan, dan terkendali (Daryanto, 2011).

Pembelajaran pada hakikatnya merupakan suatu proses interaksi antara guru dengan siswa, baik interaksi langsung seperti kegiatan tatap muka, maupun secara tidak langsung, yaitu dengan menggunakan berbagai media pembelajaran (Rusman, 2012) Keberhasilan proses belajar mengajar ditentukan oleh seberapa jauh penguasaan keterampilan dasar mengajar yang dimiliki oleh guru yang bersangkutan (Sunaryo, 1989). 
Sedangkan keterampilan dasar mengajar (teaching skills) merupakan bentuk perilaku bersifat mendasar dan khusus yang harus dimiliki oleh seorang guru sebagai modal awal untuk melaksanakan tugas-tugas pembelajarannya secara terencana dan professional (Sri, 2014). Oleh karena itu perlu kiranya pelatihan pembuatan dan pendampingan penerapan multimedia genggam Si Dio untuk tutor PKBM pada program Paket C.

Tujuan dari program ini adalah meningkatkan keterampilan tutor dalam membuat dan menerapkan multimedia berbasis IT dengan memanfaatkan smartphone berbasis android sebagai media pembelajaran bagi siswa Program Paket C di PKBM Kabupaten Kuningan. Program pelatihan pembuatan dan pendampingan penerapan multimedia genggam Si Dio (Camtasia Studio) dapat meningkatkan kualitas proses pembelajaran pada pendidikan non formal yang cenderung terabaikan dari berbagai pelatihan peningkatan kinerja tutor.

\section{METODE PELAKSANAAN}

Metode pelaksanaan kegiatan menjelaskan tahapan atau langkah-langkah dalam melaksanakan pelatihan pembuatan dan pendampingan penerapan multimedia genggam Si Dio (Camtasia Studio) berbasis android bagi tutor PKBM Program Paket C di Kabupaten Kuningan. Langkah pelaksanaan program ini adalah sebagai berikut.

\section{Survei Mitra}

Survei mitra bertujuan untuk menganalisis situasi dan keadaan mitra yang direncakan sebagai objek sasaran. Hasil dari survey mitraakan memberikan gambaran persoalan yang dihadapi oleh mitra. Kegiatan pengabdian masyarakat dengan skema Program Kemitraan Masyarakat ini akan dilaksanakan di PKBM Kabupaten Kuningan yang melaksanakan program kegiatan belajar Paket C. Mitra yang terlibat yaitu PKBM Miftahul Janah sebagai mitra 1 dan PKBM Assyifa sebagai mitra 2. Mitra berkontribusi mengarahkan tutor yang akan mengikuti pelatihan dan pendampingan penerapan multimedia genggam Si Dio (Camtasia Studio), memfasilitasi pembelajaran dengan menggunakan multimedia genggam Si Dio (Camtasia Studio), melakukan pendampingan penerapan pada saat pembelajaran, monitoring dan evaluasi penggunaan multimedia genggam Si Dio (Camtasia Studio) yang dibuat tutor.

\section{Koordinasi dengan Ketua PKBM dan Tutor}

Tujuan dari berkoordinasi dengan ketua PKBM dan tutor adalah untuk menentukan justifikasi pengusul bersama mitra dalam menentukan persoalan prioritas yang disepakati untuk diselesaikan selama pelaksanaan program PKM. Selanjutnya pengusul memberikan penjelasan kebermanfaatan dari pelaksanaan pelatihan pembuatan dan pendampingan penerapan multimedia genggam Si Dio (Camtasia Studio) berbasis android bagi tutor PKBM Program Paket C di Kabupaten Kuningan.

\section{Sosialisasi Program}

Sosialisasi program bertujuan untuk memberi informasi tentang rencana serangkaian pelaksanaan program. Sosialisasi disampaikan kepada perwakilan tutor PKBM Kabupaten Kuningan yang akan mendapat pelatihan.

\section{Pelaksanaan Program}

Pelaksanaan program pengabdian kepada masyarakat dengan Program Kemitraan Masyarakat (PKM) adalah berupa demonstrasi pelatihan pembuatan multimedia genggam Si Dio (Camtasia Studio), unjuk kerja kemampuan tutor dalam membuat multimedia genggam Si Dio, monitoring dan pendampingan perkembangan penerapan 
multimedia genggam Si Dio sebagai media pembelajaran berbasis android yang menarik dan mudah diakses oleh peserta didik. Waktu pelaksanaan yang dalam pelatihan sebanyak 4 kali pertemuan dan 2 kali pendampingan.

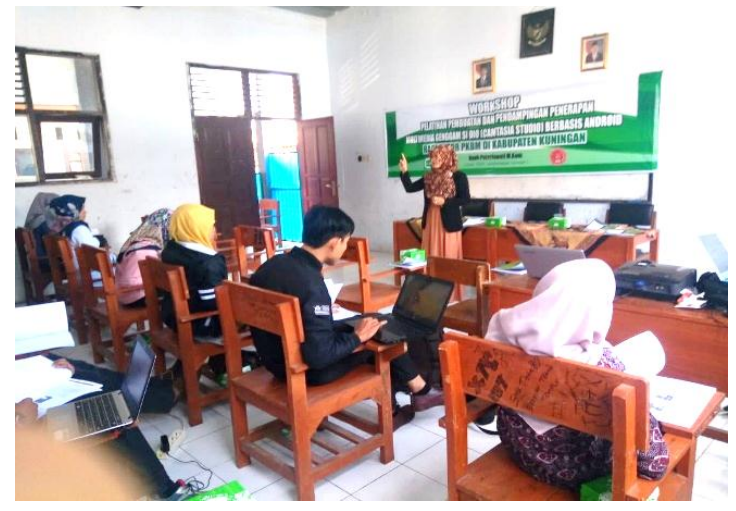

Gambar 1. Pelaksanaan Pelatihan Camtasia Studio

\section{Evaluasi Kegiatan}

Mengevaluasi perkembangan pelaksanaan pembuatan multimedia genggam Si Dio (Camtasia Studio) berbasis android yang diterapkan oleh tutor, dan memberikan masukanmasukan dari keterbatasan pelaksanaan program ini demi perbaikan untuk penerapan pada PKBM lain di Kabupaten Kuningan.

Aplikasi yang digunakan pada saat melaksanakan pelatihan pembuatan media video pembelajaran yaitu Camtasia Studio, adapun lisensi program Camtasia Studio yang digunakan masih menggunakan Trial Version. Pada saat pelakasanaan pelatihan tersebut telah disiapkan modul cetak dan modul video untuk membuat media video pembelajaran. Program pelatihan ini memfasilitasi tutor untuk menampilkan media video pembelajaran yang dibuat sebelumnya menggunakan aplikasi Camtasia Studio (Si Dio) berbasis Android.

Responden pada pelatihan pembuatan dan pendampingan pembuatan media pembelajaran dengan program Camtasia adalah sebanyak 18 tutor Paket C dari PKBM Miftahul Janah dan PKBM Asyifa yang terdapat di Kabupaten Kuningan.

\section{HASIL DAN PEMBAHASAN}

Berdasarkan rumusan masalah, maka tim pelaksana mencoba menguraikan hasil yang sudah dicapai diantaranya sebagai berikut.

\section{Langkah Meningkatkan Keterampilan Mengajar Tutor Melalui Pelatihan Pembuatan Media Pembelajaran}

Camtasia Studio merupakan software yang memiliki fitur menarik, yang didalamnya memfasilitasi pembuatan multimedia berupa video dengan penambahan animasi, gambar, musik, dan teks yang menarik perhatian dalam waktu singkat. Selain itu program ini dapat merekam layar komputer atau presentasi powerpoint sehingga tidak hanya berupa video biasa melainkan video intruksional yang sangat tepat untuk digunakan dalam mengembangkan pemahaman peserta didik terhadap suatu materi secara utuh dan holistik.

Agar tutor dapat memahami lebih mudah pembuatan media pembelajaran menggunakan Camtasia Studio maka kami menyusun buku modul panduan membuat media pembelajaran menggunakan Camtasia Studio beserta CD yang berisi tutorial Video 
membuat media pembelajaran menggunakan Camtasia Studio. Dan hasil media pemebelajaran yang dibuat oleh tutor PKBM akan diunggah kedalam aplikasi Si Dio berbasis Android oleh admin. Dibawah ini merupakan beberapa gambar pada modul pembuatan media pembelajaran Camtasia Studio. Modul pada bab pertama menjelaskan proses installasi Camtasia Studio.

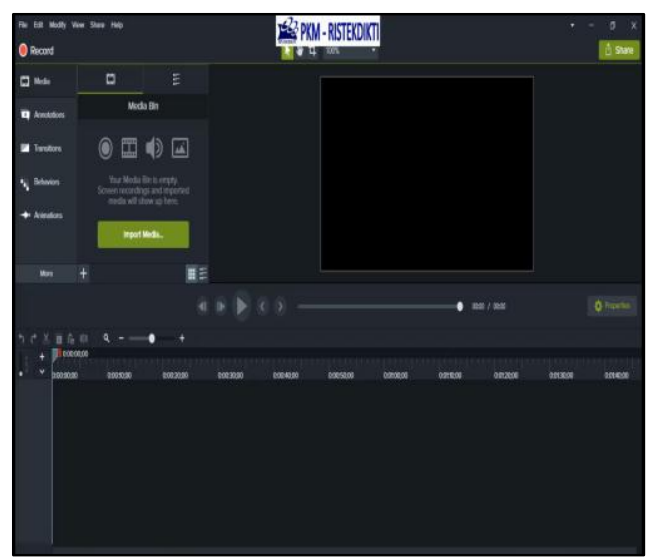

Gambar 2. Tampilan Utama Camtasia Studio Setelah di Install

Bab kedua pada modul menjelaskan setiap fungsi dasar Camtasia Studio. Diantaranya merekam Microsoft Powerpoint dan beberapa fungsi dasar lainnya. Gambar 3 merupakan beberapa gambar fungsi dasar pada Camtasia Studio.

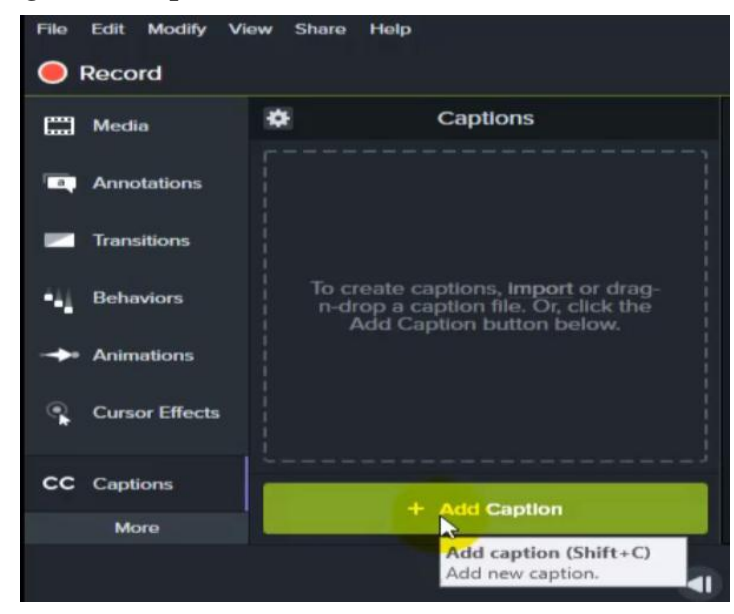

Gambar 3. Efek Caption pada Camtasia Studio

Bab ketiga pada modul menjelaskan cara menyisipkan setiap fungsi dasar Camtasia Studio. Gambar 4 merupakan gambar menyisipkan efek caption pada Camtasia Studio.

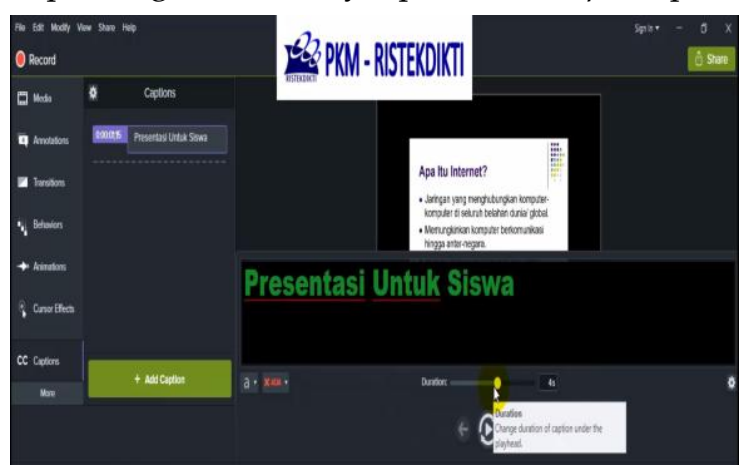

Gambar 4. Menyisipkan Efek Caption pada Camtasia Studio 
Pada modul juga dijelaskan cara menghasilkan sebuah video pembelajaran yang sebelumnya sudah dibuat. Dibawah ini salah satu gambar pada saat proses export media video pembelajaran.

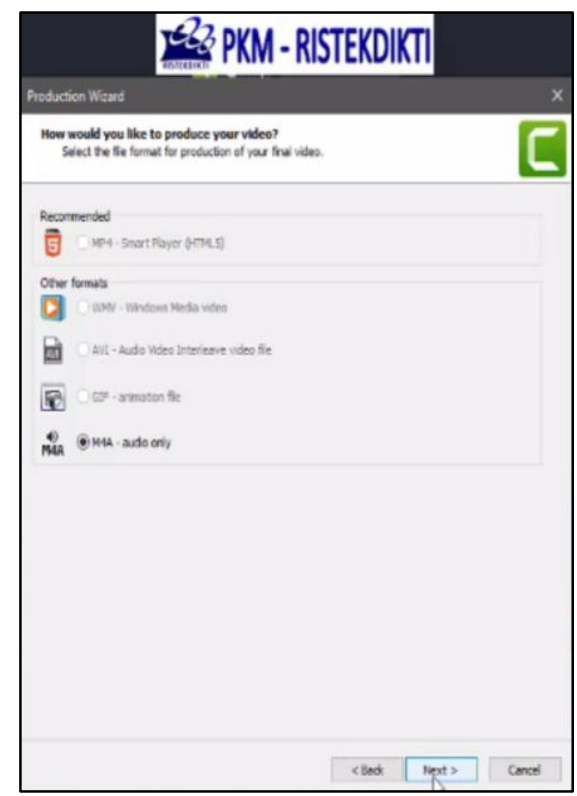

Gambar 5. Proses Export Video pada Camtasia Studio

Bab empat pada modul menjelaskan cara publikasi video, publikasi video yang digunakan pada saat pelatiahan adalah dengan menggunakan Youtube. Dimana hasil video pembelajaran yang telah dibuat oleh masing-masing tutor PKBM akan di unggah pada akun Youtube masing-masing tutor PKBM. Dibawah ini merupakan salah satu gambar proses pada saat unggah video ke Youtube.

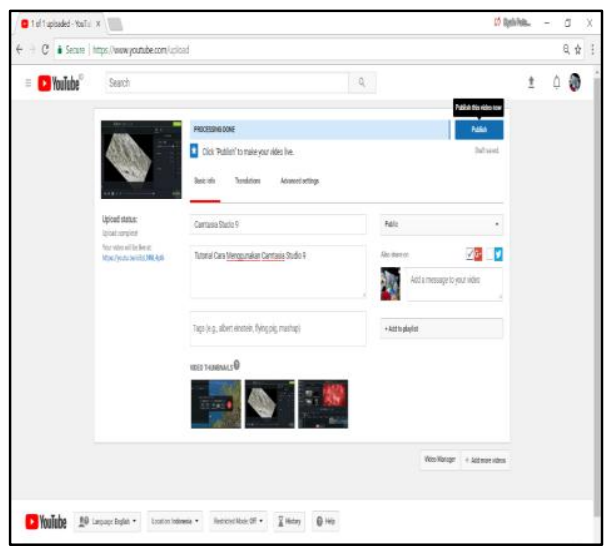

Gambar 6. Proses Publikasi Video

\section{Langkah Meningkatkan Kualitas Pembelajaran Melalui Penerapan Multimedia Genggam Si Dio Berbasis Android pada PKBM di Kabupaten Kuningan}

Pelatihan yang kami laksanakan melalui beberapa tahap yaitu koordinasi dengan pihak PKBM, menentukan jadwal pengabdian,pelaksanaan pelatihan Tahap I, pelaksanaan pelatihan tahap II, penerapan multimedia genggam Si Dio, dan evaluasi.

Pelatihan ini kami laksanakan untuk meningkatkan keterampilan tutor dalam membuat media pembelajaran menggunakan Camtasia Studio, dan menerapkan 
multimedia berbasis IT dengan memanfaatkan smartphone berbasis android sebagai media pembelajaran bagi siswa Program Paket C di PKBM Kabupaten Kuningan. Program pelatihan pembuatan dan pendampingan penerapan multimedia genggam Si Dio (Camtasia Studio) dapat membantu memperbaiki dan peningkatkan kualitas proses dari program kesetaraan Paket C. Di bawah ini tampilan layar media genggam Si Dio Berbasis Android.

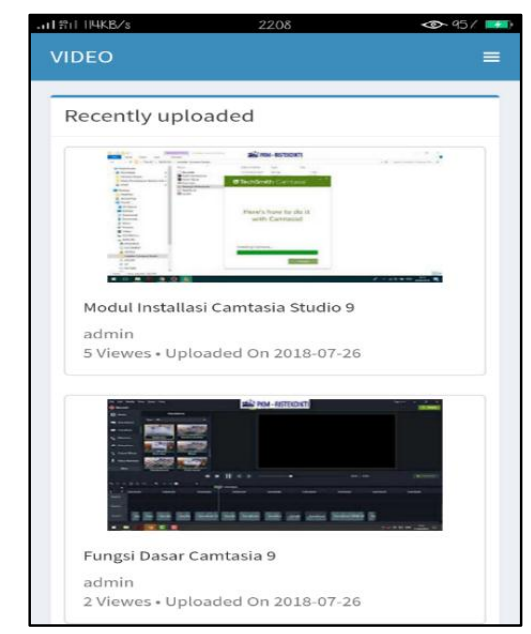

Gambar 7. Tampilan Layar Multimedia Genggam Si Dio Berbasis Android

Dari beberapa pertemuan yang sudah dilakukan pada saat pelatihan, tutor PKBM sangat antusias ketika mengikuti pelatihan pembuatan dan penerapan multimedia genggam Camtasia Studio.

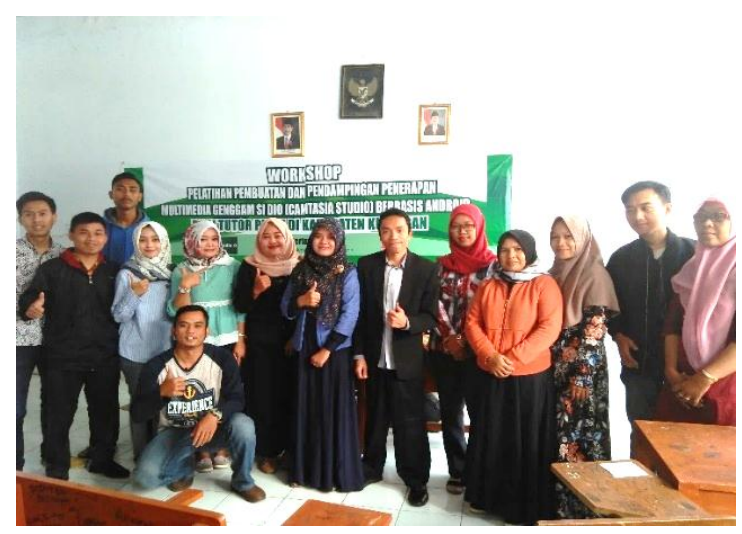

Gambar 8. Foto Bersama Tutor PKBM

Berdasarkan hasil wawancara yang dilakukan dengan pihak tutor PKBM ketika pelatihan, tutor PKBM bersedia menerapkan multimedia genggam Si Dio dalam kegiatan belajar mengajar. Dan bedasarkan hasil angket yang diberikan kepada tutor PKBM setelah pelatihan pembuatan dan penerapan multimedia genggam Camtasia Studio, dapat disimpulkan hasilnya cukup baik bagi tutor PKBM di Kabupaten Kuningan.

Setelah pelaksanaan pelatihan pada tutor PKBM diharapkan dapat memperbaiki kualitas dan hasil pembelajaran pada Paket $C$ di kedua mitra PKBM melalui penerapan media pembelajaran menggunakan Camtasia Studio. Hal tersebut didasarkan pada berbagai penelitian terdahulu bahwa penggunaan media pembelajaran memberikan pengaruh pada peningkatan performa akademik peserta didik (Yekyastuti, 2016). 


\section{Respon Tutor terhadap Pelatihan Pembuatan dan Pendampingan Penerapan Multimedia Genggam Si Dio}

Setelah pelaksanaan pelatihan dan pendampinan penerapan Camtasia Studio, kami memberikan angket kepada 18 peserta yang berisi 15 pernyataan. Tujuan dari pemberian angket ini adalah untuk mengatahui bagaimana respon dari tutor peserta pelatihan terhadap pelaksanaan dan mengetahui seberapa besar manfaat yang mereka rasakan. 15 pernyataan dalam angket diturunkan dari 5 indikator yaitu senang terhadap program Camtasia Studio, kebermanfaatan Camtsia untuk membuat bahan ajar, kemudahan Camtasia Studio untuk penyampaian materi, kemudahan penggunaan Camtasia Studio dalam pembuatan bahan ajar dan kesulitan penggunaan Camtasia Studio. Adapuun presentase hasil jawaban responden dapat dilihat pada Tabel 1.

Tabel 1. Hasil Jawaban Angket Responden

\begin{tabular}{|c|c|c|c|c|c|c|}
\hline \multirow{2}{*}{ No. } & \multirow{2}{*}{ Indikator } & \multicolumn{5}{|c|}{ \% Jawaban Responden } \\
\hline & & SS & S & $\mathrm{R}$ & TS & STS \\
\hline 1 & Senang terhadap program Camtasia Studio & 11 & 61 & 6 & 22 & 0 \\
\hline 2 & $\begin{array}{l}\text { Kebermanfaatan Camtasia Studio untuk } \\
\text { membuat bahan ajar }\end{array}$ & 17 & 65 & 7 & 11 & 0 \\
\hline 3 & $\begin{array}{l}\text { Kemudahan Camtasia Studio untuk } \\
\text { penyampaian materi }\end{array}$ & 0 & 72 & 6 & 16 & 6 \\
\hline 4 & $\begin{array}{l}\text { Kemudahan penggunaan Camtasia Studio } \\
\text { dalam pembuatan bahan ajar }\end{array}$ & 12 & 60 & 4 & 16 & 8 \\
\hline 5 & Penggunaan Camtasia Studio menyulitkan & 0 & 22 & 7 & 54 & 17 \\
\hline
\end{tabular}

Berdasarkan Tabel 1 dapat disimpulkan bahwa dari 5 indikator respon tutor terhadap pelatihan pembuatan dan pendampingan penerapan multimedia genggam $\mathrm{Si}$ Dio berbasis android ini sebagian besar merespon secara positif. Sebanyak $61 \%$ tutor merespon setuju dan $11 \%$ merespon sangat setuju bahwa mereka merasa senang membuat media pembelajaran menggunakan Camtasia Studio, sehingga mereka tertarik untuk lebih serius dalam membuat materi video pembelajaran. Setelah dilakukan pendampingan penerapan media pembelajaran dengan Camtasia, mereka merasa lebih senang dalam penyampaian materi bahan ajar melalui video pembelajaran Camtasia Studio dibandingkan dengan menerangkan langsung kepada siswa. Sebanyak 65\% tutor merespon setuju bahwa Camtasia bermanfaat untuk membuat bahan ajar, karena cara membuat media pembelajaran dengan Camtasia Studio ini cepat dan dapat memacu mereka untuk membuat materi bahan ajar lebih menarik lagi.

Sebanyak $71 \%$ tutor merespon setuju bahwa materi bahan ajar lebih mudah disampaikan melalui video pembelajaran dengan menggunakan Camtasia Studio. Dimana $60 \%$ tutor merespon setuju dan $11 \%$ merespon sangat setuju bahwa membuat media pembelajaran dengan menggunakan Camtasia Studio membuat mereka lebih bebas berkreasi dalam membuat materi bahan ajar, sekaligus dapat membantu dan bertukar pikiran dengan rekan tutor lainnya yang merasa kesulitan dalam memahami pembuatan video pembelajaran Camtasia Studio. Namun masih ada 29\% tutor yang merespon setuju bahwa masih enggan belajar karena bingung dan tidak memiliki cukup waktu untuk belajar membuat media pembelajaran dengan Camtasia Studio. Hal ini dimungkinkan karena beberapa tutor berusia tidak lagi muda dan memiliki kesibukan yang lain. 


\section{SIMPULAN}

Berdasarkan hasil pembahasan kuisioner diatas didapatkan hasil perhitungan sebesar $71 \%$ yang menyatakan setuju bahwa materi bahan ajar lebih mudah disampaikan melalui multimedia genggam SiDio berbasis android ini cukup baik digunakan oleh para tutor PKBM dalam menyampaikan materi pembelajaran video dengan memanfaatkan teknologi smartphone saat ini.

\section{REFERENSI}

Anwariningsih, H. S. (2014). Kesiapan penggunaan ICT pada sekolah dasar di daerah rural dalam perubahan paradigma pembelajaran. In E. S. Rahayu (Ed.), Good Governance Menuju Kesejahteraan dan Kemandirian Pertanian Indonesia. Paper presented at Seminar Nasional dan Call For Papers UNIBA, 8 October 2014 (pp. 11-17). Surakarta: Universitas Islam Batik.

Busyaeri, A., Udin, T., \& Zaenudin, A. (2016). Pengaruh penggunaan video pembelajaran terhadap peningkatan hasil belajar mapel IPA di MIN Kroya Cirebon. Al Ibtida: Jurnal Pendidikan Guru MI, 3(1), 116-137.

Daryanto. (2011). Media pembelajaran. Bandung: Sarana Tutorial Nurani Sejahtera.

Depdiknas. (2006). Pendidikan kesetaraan, Jakarta: Direktorat Pendidikan Kesetaraan, Ditjen. PLS.

Disdik Jakarta. (2016). Kualifikasi pendidikan tutor paket C. Jakarta: Disdik Provinsi DKI Jakarta.

Kustiono. (2010). Media pembelajaran konsep, nilai edukatif, klasifikasi, praktek, pemanfaatan dan pengembangan. Semarang: UNNES Press.

Rusman. (2012). Model-model pembelajaran mengembangkan profesionalisme guru. Jakarta: Rajagrafindo Persada.

Sukamto. (2004). Peningkatan kualitas pembelajaran. Jakarta: Depdiknas.

Sunaryo. (1989). Strategi belajar mengajar dalam pengajaran ilmu pengetahuan sosial. Jakarta: Dikti.

Surjono, H. D. (2010). Pemanfaatan teknologi informasi dan komunikasi dalam peningkatan kualitas pembelajaran. Magelang: MGMP Kota Magelang.

Winarno, D., Yasid, A., Marzuki, R., Rini, S. E. S., \& Alimah, S. (2009). Teknik evaluasi multimedia pembelajaran. Yogyakarta: Genius Prima Media.

Yektyastuti, R., \& Ikhsan, J. (2016). Pengembangan media pembelajaran berbasis android pada materi kelarutan untuk meningkatkan performa akademik siswa SMA. Jurnal Inovasi Pendidikan IPA, 2(1), 88-99. 